\title{
In defense of succinylcholine
}

\author{
Richard Falkenstein, MD, FRCP
}

Received: 18 August 2016/ Accepted: 12 October 2016/Published online: 21 October 2016

(C) Canadian Anesthesiologists' Society 2016

\section{To the Editor,}

I was intrigued by the recent editorial in the Journal by Drs Hung, McKeen, and Huitink, ${ }^{1}$ especially their prediction that, with the arrival of sugammadex, succinylcholine (Sux) "will fade into obscurity." Like all great editorials, theirs is erudite, topical, and provocative. However, I would like to offer a different perspective.

Adopting a similar "relational" analogy to that used by Hung et al., I am inclined to describe Sux as an "old friend." Like myself and others with whom I have relationships, Sux is not perfect. However, during the 30odd years that I have been giving anesthetics, I have come to understand my friend's nature a little, and I no longer wish Sux was somehow different. Rather, I accept $\operatorname{him}^{\mathrm{A}}$ as he is and try to use those unique elements he brings to the relationship for the benefit of my patients.

When I invite Sux to a party, I always make sure that a couple of other friends arrive before he does. A nondepolarising neuromuscular blocker (in very small amounts) and a systemic bolus of local anesthetic are the two friends who seem to "tame" many of Sux's wilder tendencies. That is, when they are around, he seems less likely to talk religion and politics (or, in less metaphorical terms, to incite problems with potassium, intracranial pressure, and gastric pressure, among others). Although I cannot completely rely on these two friends to keep Sux from making any trouble, when they are around Sux can

This letter is accompanied by a reply. Please see Can J Anesth 2017; 64: this issue.

R. Falkenstein, MD, FRCP ( $₫)$

University of Calgary Cumming School of Medicine, Calgary,

$\mathrm{AB}$, Canada

e-mail: richard.falkenstein@ahs.ca usually be tolerated. Of course, there are always some parties (i.e., burns) where even a modified amount of his antics would be intolerable - so Sux does not get invited to those.

There is another friend I am happy to have in the house when $S u x$ is around. Indeed, pseudocholinesterase ("Pseudo") doesn't even have to be invited - he is already there. When Pseudo - the real one, not one of his imitators (i.e., a genetic variant) - is present, Sux never sticks around too long, thus reducing his chance to become troublesome. Pseudo is a real gift, especially as he really does not seem to have any other job than making sure Sux does not overstay his welcome. Pseudo works hard to do an adequate job, even when there is not much of him around (e.g., with liver disease) or when other bad things are going on in the house (i.e., other organ compromise).

If it takes all these other friends to keep Sux from acting up, why do I not give up on him? After all, there is this other guy, rocuronium ("Roc"), who can bring some of what Sux brings to the party. Some say that his act is not quite as good as Sux's and that he is always late, unless you give a lot (of encouragement). If you do that, however, it can be difficult to get him to leave. Also, Roc can make it a bit difficult to tell how adequate (i.e., depth of anesthesia) the party is as it goes along. Roc tends to inhibit some other guests (i.e., motor nerves), so he cannot be present if you want them to express themselves (e.g., obtain motor evoked potentials). It was getting to be so much trouble for me to make sure Roc was completely gone (i.e., when I did not want him around anymore) that I stopped inviting him to any of my parties. Indeed, whenever possible, I

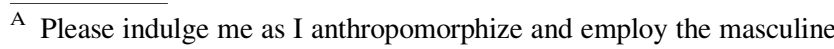
pronoun.
} 
prefer to provide my anesthetics without maintenance neuromuscular blockade.

Recently, a new name is in the news - sugammadex ("Sug"). This fellow claims to be able to make Roc "wrap it up" pretty much any time. For this ability, however, Sug charges a premium, especially as you may need a lot of him, particularly when you have a lot of Roc around. Sug is not already "in the house" (as Pseudo is) but must be added. It may be too early to tell just how much we can rely on Sug when other "bad things are going on in the house." Splurging on Sug might be a bit more enticing if we were more certain about just how often Sux actually gets out of hand. Unfortunately, Sux may be a bit like that juvenile delinquent living in the neighbourhood who has this reputation for bad behaviour such that when undesirable things start happening he is the first to be blamed - even if his involvement turns out to be marginal (or even nonexistent). Accordingly, his reputation results in him being more easily framed when blame needs to be shifted or a "cover-up" is deemed to be in order. Arguably, we prefer to assign blame to a drug itself, rather than to our handling of said drug.

The Hung et al. editorial begins with the description of an alarming incident related (at least temporally) to administration of a small second dose of Sux. I found myself more disturbed by the potential "legal" ramifications to the anesthesiologist involved than by the consequences to the patient. This made me feel a bit guilty, as I do when I contemplate avoiding a drug or technique because I am sometimes more concerned about potential risks to me than the potential benefits to my patient. My impression is that there may have been a significant amount of "over-reaction" (by all concerned) to the incident described.

Personally, I have never seen more than "two monitor screens" of asystole in response to a second (or third, or fourth, or fifth...) dose of Sux. Thirty seconds of anything, good or bad, seems hardly worth getting excited over. One wonders if maintaining (or even supplementing) the cardiac conducting system's “ionic milieu" (i.e., ensuring homeostasis of sodium, potassium, calcium, magnesium, $\mathrm{pH}$, and so on) could be important in reducing the potential for prolonged Sux side effects on heart rate or rhythm.

There is no question that Sux can be involved in some very bad situations. Information is instantly available worldwide these days, including Sux-related "horror stories." Practitioners may overvalue such tales, especially if the tales are not moderated - for instance, if one has not given the drug often themselves or has had little access to mentors and institutions willing to attest to an overwhelming number of uneventful administrations of the drug.
I suggest that some of our concerns about Sux may be related to "human factors." For example, such factors can evoke sufficient concern to prevent a few of us from flying on airplanes - despite acknowledging that cars are more often involved in accidents. Such individuals are comforted by the notion that accidents in an automobile are less likely to be devastating. Similarly, some practitioners (consciously or unconsciously) may be concerned that "mysterious forces" in the universe will ensure that, if Sux is used in a clinical situation that does not absolutely require it, there will be a disaster and their actions will be difficult to justify post hoc.

This seems more like superstition than science. For those who need a good reason to use Sux, I offer the same two reasons proposed, albeit somewhat reluctantly, by our editorialists: faster onset of better intubating conditions. Sometimes seconds do count - in my opinion, the interval between induction and intubation is always one of those times.

Is anyone but me worried about what effect the possible extinction of Sux might have on the use of alternate forms of airway management during general anesthesia besides endotracheal intubation? How many anesthesiologists are comforted by Sux's presence, even when they do not plan to use it? Is the Roc/Sug combination really likely to be a great alternative for all situations requiring airway interventions?

Appropriately, our editorialists call for "thorough assessment ... and planned strategies prior to the intervention." I suspect, however, that we pursue therapies that appear to be free of any side effects - or the potential for complications - not so much because we need such therapies in our calm, rational moments. Rather, we hope such therapies may be safer in the hands of the situationally inexperienced, the temporarily unanalytical, or the overly stressed. Honestly, I can be all of those on any given day. On such days, I need forgiveness - another essential element in relationships. If I want the forgiveness of Pseudo, I have to forgive Sux his occasional outbursts. I think it remains to be seen if $S u g$ will be as forgiving as Pseudo has been in as many clinical circumstances.

Finally, our editorialist's suggestion that we "deserve better" from a relationship than what Sux provides seems like a bit of hubris to me. I may indeed deserve better after I have contributed everything I can to the relationship, but the neuromuscular junction (NMJ) is a very complicated place that I probably just do not understand as well as I should. I think the fact that most patients seem to tolerate the NMJ perturbations we make speaks more to the redundancy of its systems than to our mastery of them. Mostly, I try to be sure that the NMJ has what it needs to work properly (i.e., the right concentrations of many of those same ions previously referred to as useful to the 
electrical activity of the heart) and then just try to leave it alone. Perhaps when I (we) understand more, we may justifiably ask for more.

In the meantime, I think I can unequivocally say that my old, good (though clearly not perfect) friend Sux has helped many more of my patients than he has harmed. Most relationships worth having involve some work. If we abandon a relationship for the wrong reasons, we risk losing something valuable - something that may be very difficult to replace.

Conflicts of interest None declared.
Editorial responsibility This submission was handled by Dr. Hilary P. Grocott, Editor-in-Chief, Canadian Journal of Anesthesia.

\section{Reference}

1. Hung O, McKeen D, Huitink J. Our love-hate relationship with succinycholine: Is sugammadex any better? Can J Anesth 2016; 63: 905-10. 